\title{
SEISMIC EVALUATION AND RETROFITTING CODAL PROVISIONS -STATE OF THE ART
}

\author{
Haider A. Abass ${ }^{1}$ and Husain K. Jarallah ${ }^{2}$ \\ ${ }^{1}$ M.Sc. Student at Department of Civil Engineering, College of Engineering, Mustansiriyah \\ University, Baghdad - Iraq. E-mail: hiaderaabass@ uomustansiriyah.edu.iq \\ ${ }^{2}$ Asst.Prof.Dr at Department of Civil Engineering, College of Engineering, Mustansiriyah \\ University, Baghdad - Iraq. E-mail: khalfdce1@ gmail.com

\section{HTTPS://DOI.ORG/10.30572/2018/KJE/130103}

\begin{abstract}
Seismic evaluation is one of the important ways to validate that buildings can resist the earthquake loads. The seismic evaluation is classified into global and local checking; the global includes the overall lateral deflection and inter-story drift, the local involves the plastic hinge formed in the structural elements (beams, columns, shear wall, etc.) of the buildings. This paper includes the seismic evaluation techniques according to previous international codes. These codes include ATC-40, FEMA-273, FEMA-356, FEMA-440, ASCE41-13, Euro code 8 , Japanese standard code, and Newzland code. This study showed that the seismic evaluation techniques introduced in FEMA-440 and the Japanese standard code are almost complete compared with the other techniques in the other codes.
\end{abstract}

KEYWORDS: Capacity Spectrum Method, Seismic Evaluation, Displacement Coefficient Method, Capacity Curve, Pushover Analysis. 


\section{INTRODUCTION}

Although an elastic analysis gives a good indication of the elastic capacity of structures and indicates where first yielding will occur, it cannot predict failure mechanisms and account for redistribution of forces during progressive yielding (Giordano M., et al., 2008). Practicing engineers use inelastic analysis procedures for the seismic evaluation and design of upgrades of the existing building and other structures, as well as the design of new construction. The use of inelastic procedures helps to demonstrate how the building behaves by identifying modes of failure and the potential for progressive collapse (Hamraj M. 2014). It helps engineers to understand how the structures will behave when subjected to major earthquakes, where it is assumed that the elastic capacity of the structure will be exceeded. Pushover methods are especially useful for the evaluation of existing buildings (usually not originally designed with seismic requirements) (Mwafy A.M. and Elnashai. A.S. 2001). Pushover analysis is based on the assumption that the dynamic response of the structure is controlled by the elastic fundamental mode, which is the case for most regular buildings (Elnashai A. S. and Di Sarno L. 2008). In this study, the important codes will be reviewed for the seismic evaluation and retrofitting of the existing buildings.

\section{RESEARCH SIGNIFICANCE}

This research illustrates the differences and the sensitivity of seismic performance levels of the buildings due to the use of various techniques of seismic evaluation and retrofitting relied on various international codes.

\section{CODAL PROVISIONS}

It is widely recognized that ground shaking in existing buildings located in seismic regions may induce unacceptable levels of damage. Several reasons have been attributed to this vulnerability, such as insufficient strength and stiffness, poor detailing of reinforcement, plan and elevation irregularities, the dominance of brittle failure modes over ductile ones, etc. (Yön, B., et al., 2017). Various codes display the principle concepts to find the seismic performance level of the buildings.

\subsection{APPLIED TECHNOLOGY COUNCIL (ATC-40, 1996)}

Capacity Spectrum Method (CSM) has gained considerable popularity amongst pushover users and the ATC40 guidelines included the nonlinear static procedure that should be applied. The CSM was created to describe a structure's first mode response based on the 
assumption that the first mode response of the structure is the fundamental mode of vibration.. The steps of the capacity spectrum method are described herein:

Step (1): Seismic Data

A MDOF model of the building must be developed including the nonlinear force-deformation relationship for structural elements under monotonic loadings (see Fig. 1a). An elastic acceleration response spectrum is also required corresponding to the seismic action under consideration (see Fig. 1b).

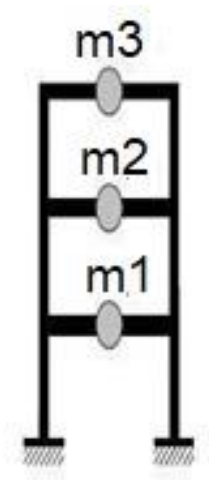

a)

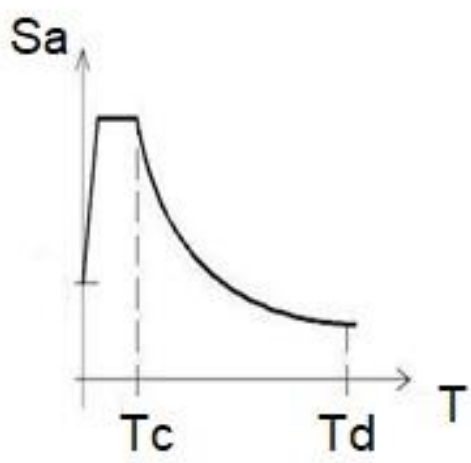

b)

Fig. 1-a): MDOF Model of the Building; b) Elastic Acceleration Response Spectrum.

Step (2): Seismic demand in acceleration displacement response spectrum (ADRS) format.

The seismic demand is defined with a response spectrum in the format accelerationdisplacement (ADRS). For SDOF, the displacement spectrum can be computed from the acceleration spectrum using equation (1):

$$
S_{d}=\frac{T^{2}}{4 \pi^{2}} S_{a}
$$

Where $S_{a}$ and $S_{d}$ are the values for the elastic acceleration and displacement spectrum, respectively.

Step (3): Pushover Analysis.

A conventional non-adaptive force-based pushover analysis is performed by applying a monotonically increasing pattern of lateral forces to the structure. Lateral forces are applied in proportion to the story masses and the square height of the floor by using equation (2):

$$
\mathrm{F}_{i}=\frac{\mathrm{m}_{\mathrm{i}} \mathrm{h}_{\mathrm{i}}^{2}}{\sum_{\mathrm{j}=1}^{n} \mathrm{~m}_{\mathrm{j}} \mathrm{h}_{\mathrm{j}}^{2}}
$$


where $m_{i}$ and $h_{i}$ are the mass and height of $i^{\text {th }}$ floor. The symbol (i) reflects the story (mass and height) under consideration while the denominator $(j)$ reveals the summation of stories (masses and heights) of the building.

From the pushover analysis, the capacity curve was obtained that represents the base shear and the displacement at the center of mass of the roof.

Step (4): Equivalent SDOF system

The structural capacity curve is expressed in terms of roof displacement and base shear. It is converted into a SDOF curve in terms of spectral displacements and spectral accelerations, which is called the capacity spectrum. The transformations are made using the following equations:

$$
\begin{aligned}
& P F_{1}=\left[\frac{\sum_{i=1}^{N}\left(w, \phi_{i 1}\right) / g}{\sum_{i=1}^{N}\left(w_{i} \phi_{i 1}^{2}\right) / g}\right] \\
& \alpha_{1}=\frac{\left[\sum_{i=1}^{N}\left(w_{i} \phi_{i 1}\right) / g\right]^{2}}{\left[\sum_{i=1}^{N} w_{i} / g\right]\left[\sum_{i=1}^{N}\left(w_{i} \phi_{i 1}^{2}\right) / g\right]} \\
& S_{a}=\frac{V / W}{\alpha_{1}} \\
& S_{d}=\frac{\Delta_{\text {roof }}}{P F_{1} \phi_{\text {roof } .1}}
\end{aligned}
$$

(see Fig. 2), it shows that the participation factor and modal mass coefficient differ according to the relative inter-story drift over the height of the building. For example, the linear distribution of inter-story drift along with the height of the building $\alpha 1 \approx 0.8$ and PF $1 \approx 1.4$.

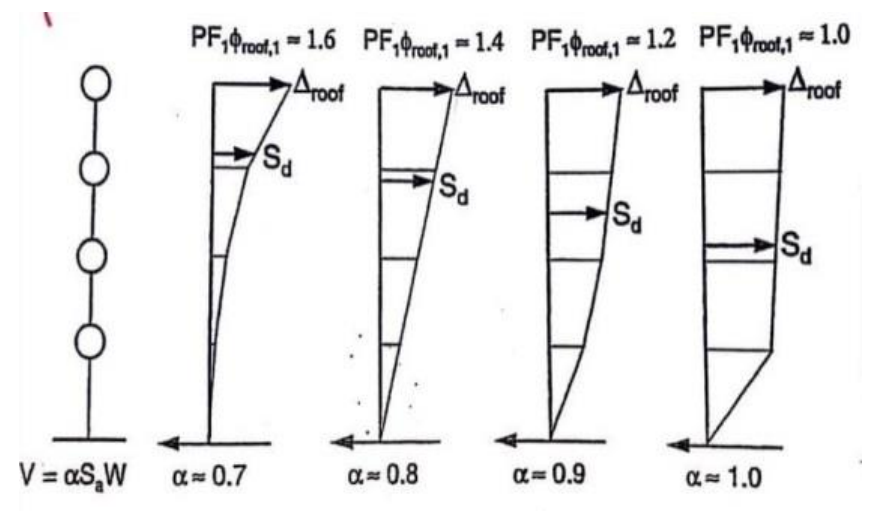

Fig. 2. Modal Participation Factors and Modal Mass Coefficients. 
To convert MDOF capacity curve to SDOF capacity curve in the format (capacity spectrum) of the Acceleration-Displacement Response Spectra (ADRS) format (Sa versus Sd), the modal participation factor $\mathrm{PF}_{1}$ and the modal mass coefficient $\alpha$ must first be calculated by using equations(3) and (4). Afterward, each point of the MDOF capacity curve (V, $\Delta$ roof) was calculated the associated point $(\mathrm{Sa}, \mathrm{Sd})$ of the capacity spectrum according to equations (5) and (6).

Step (5): Estimation of Damping and Response Spectrum Reduction:

ATC-40 defines equivalent viscous damping to represent this combination; it can be calculated using equation (7):

$$
\beta_{e q}=\beta_{1}+5
$$

ATC-40 introduces the concept of effective viscous damping that can be obtained by multiplying the equivalent damping by a modification factor $\mathrm{k}$ by using equation (8):

$$
\beta_{\text {eff }}=k \beta_{1}+5
$$

Where 5\% viscous damping is inherent in the structure (assumed to be constant). The hysteretic damping represented as equivalent viscous damping can be calculated by using equation (9):

$$
\beta_{1}=\frac{1}{4 \pi} \cdot \frac{E_{D}}{E_{S_{0}}}
$$

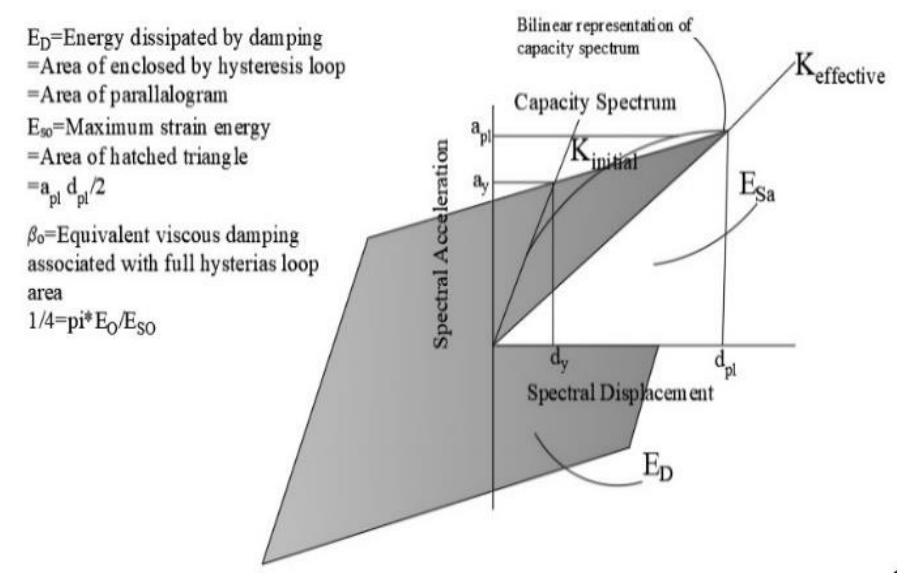

Fig. 3. Derivation of Damping for Spectral Reduction (ATC-40, 1996).

The physical meaning of both $E_{D}$ and $E_{S 0}$ is represented in (see Fig. 3). $E_{D}$ is the energy dissipated by the structure in a single cycle of motion, that is, the area bounded by a single hysteresis loop. $\mathrm{E}_{\mathrm{S} 0}$ is the maximum strain energy related to that cycle of motion ,that is, the 
area of the hatched triangle. (see Fig. 4) shows the derivation of energy dissipated by damping.

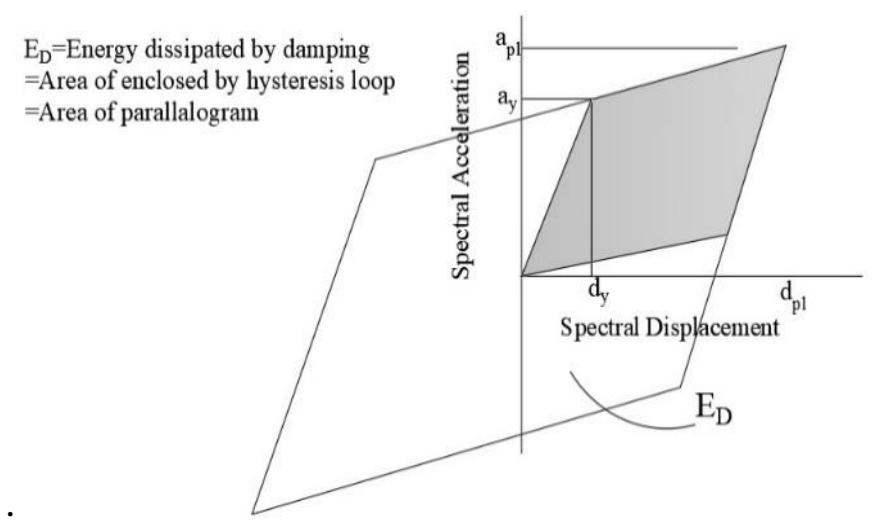

Fig. 4. $E_{D}$ is the Energy Dissipated by Damping Derivation (ATC-40, 1996).

Therefore, $\beta 1$ can be written as in equation (10):

$$
\beta_{1}=\frac{63.7\left(a_{y} d_{p i}-d_{y} a_{N}\right)}{a_{p i} d_{p i}}
$$

The effective damping can be written as equation (11):

$$
\beta_{\text {eff }}=\frac{63.7 k\left(a_{y} d_{p i}-d_{y} a_{p i}\right)}{a_{p i} d_{p i}}+5
$$

The k-factor depends on the structural behavior of the building, which is related to the seismic resisting system quality and the ground shaking duration. ATC40 defines three categories of structural behavior:

Type A represents stable, reasonably full hysteresis loops, type B represents a moderate reduction of area, and type $\mathrm{C}$ represents poor hysteretic behavior with a significant reduction of loop area (severely pinched). Table 1 indicates the ranges and limits for the values of $\mathrm{k}$ specified to the three structural behavior types.

Table 1. Modification factor $k$.

\begin{tabular}{ccc}
\hline Structural Behavior Type & $\beta_{1}$ & $\boldsymbol{k}$ \\
\hline & $\leq 16.25$ & 1.0 \\
\cline { 2 - 3 } Type A & \multicolumn{2}{c}{1.13} \\
& $>16.25$ & $-\frac{0.51\left(a_{y} d_{p i}-d_{y} a\right.}{a_{p i} d_{p i}}$ \\
\hline & $\leq 2.5$ & 0.67
\end{tabular}




\begin{tabular}{ccc}
\hline Type B & & 0.845 \\
& $>2.5$ & $-\frac{0.446\left(a_{y} d_{p i}-d_{y}\right.}{a_{p i} d_{p i}}$ \\
\hline Type C & Any value & 0.33
\end{tabular}

Step (6): Numerical Derivation of Spectral Reductions

As seen in Equations (12) and (13), the spectral reduction factors are determined.

$S R_{A}=\frac{3.21-0.68 \ln (\beta e f f)}{2.12}=\frac{3.21-0.68 \ln \left[\frac{63.7 k\left(a_{y} d_{p i}-d_{y} a_{p i}\right)}{a_{m} d_{p i}}+5\right]}{2.12} \geq$ Value in Table(2)
$S R_{v}=\frac{2.31-0.41 \ln (\beta e f f)}{1.65}=\frac{2.31-0.41 \ln \left[\frac{63.7 k\left(a_{y} d_{r i}-d_{y} a_{p i}\right)}{a_{p i} d_{p i}}+5\right]}{1.65} \geq$ Value in Table(2)

Values for $S_{\mathrm{RA}}$ and $\mathrm{S}_{\mathrm{Rv}}$ should be greater than or equal to those listed in Table 2.

Table 2. $S_{R A}$ and $S_{R v}$.Values

\begin{tabular}{ccc}
\hline Form of Structural Action & $\boldsymbol{S R}_{\boldsymbol{A}}$ & $\boldsymbol{S R}_{\boldsymbol{v}}$ \\
\hline Type (A) & $0 . .33$ & $0 . .50$ \\
Type (B) & $0 . .44$ & $0 . .56$ \\
Type (C) & $0 . .56$ & $0 . .67$
\end{tabular}

Step (7): Calculation of the target displacement:

The calculation of the target displacement is an iterative process, where it is necessary to estimate a first trial performance point. For this purpose, there are several options one can use:

1. The first trial performance point can be estimated as the elastic response spectrum corresponding to the elastic fundamental period. The response spectrum is defined for the viscous damping level considered (in buildings are considered as 5\%);

2. The first trial equivalent damping value was considered and calculated the respective reduction factor. By Multiplying the elastic spectrum by this reduction factor and intersect the capacity curve with the reduced spectrum. The intersection corresponds to the first trial performance point. The capacity curve is then bi-linearized for this point, new effective damping can be computed and hence a new reduction factor can be applied. The new intersection between the capacity curve and the new reduced spectrum leads to a new performance point. If the target displacement calculated within a tolerable range (for example within $5 \%$ of the displacement of the trial performance point), then the performance point can be obtained. (see Fig. 5) represents the process schematically. 


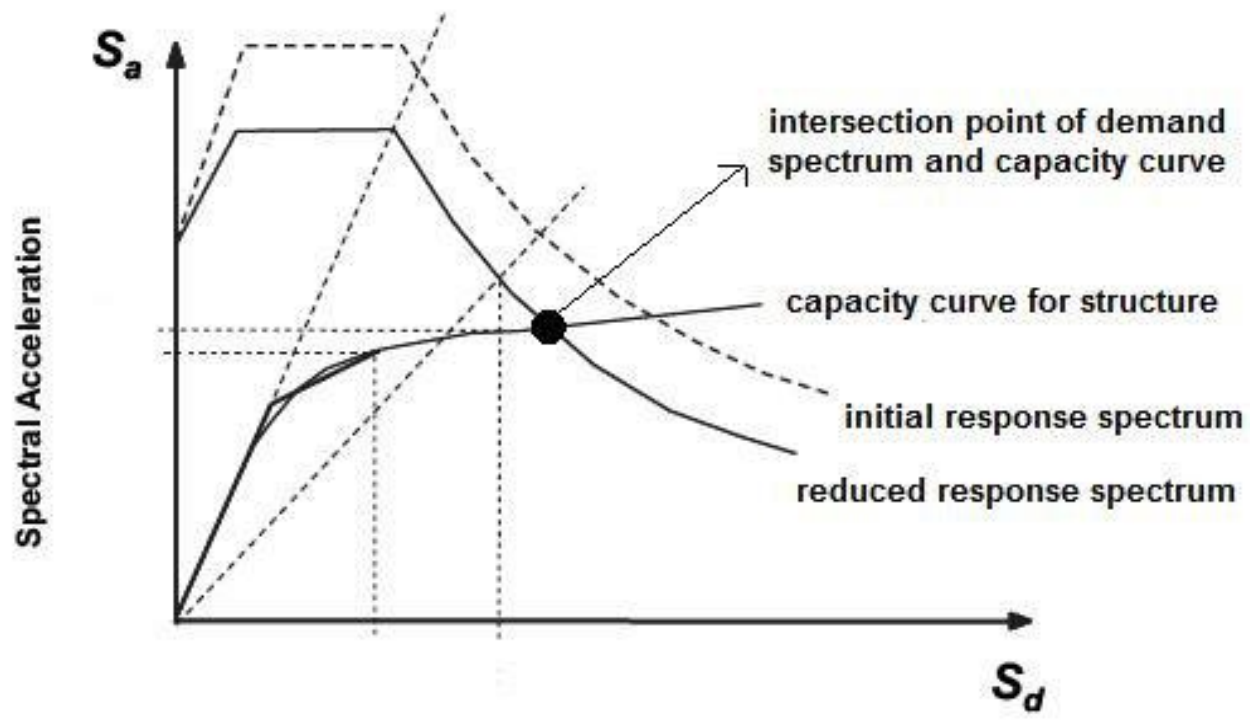

Spectral Displacement

Fig. 5. Target displacement computed by CSM.

Step (8): Determination of MDOF response parameters in correspondence to the Performance Point (converted from SDOF to MDOF)

At this stage of the procedure, the MDOF pushover curve to the point consistent with the value of the SDOF target displacement (calculated in the previous step) multiplied by the transformation factor. For this step, building's performance results was obtined such as deformations, inter-story drifts, and chord rotations.

\subsection{FEDERAL EMERGENCY MANAGEMENT AGENCY (FEMA273/356, 2001)}

The Displacement Coefficient Method (DCM) is the primary nonlinear static procedure presented in FEMA 356. The target displacement $\delta$, at each floor level shall be calculated by using equation (14):

$\delta_{t}=C_{0} C_{l} C_{2} C_{3} S_{a} \frac{T_{e}^{2}}{4 \pi^{2}} g$

where:

$\mathrm{C}_{0}=$ Modification factor to associate spectral displacement of an equivalent SDOF system to the roof displacement of the building MDOF system determined using one of the following procedures:

1. The first modal participation factor at the control point level.

2. The appropriate value from Table 3. 
Table 3. Values for Modification Factor $\mathbf{C}_{0}$.

\begin{tabular}{cc}
\hline No.of stories & Modification factor \\
\hline 1.0 & 1.0 \\
2.0 & 1.2 \\
3.0 & 1.3 \\
5.0 & 1.4 \\
+10 & 1.5 \\
\hline
\end{tabular}

$\mathrm{C}_{1}=$ Modification factor to relate estimated maximum inelastic displacements to displacements calculated for linear elastic response:

$=1.0$ for $\mathrm{T}_{\mathrm{e}} \geq \mathrm{T}_{\mathrm{S}}$

$=\left[1.0+(\mathrm{R}-1) \mathrm{T}_{\mathrm{S}} / \mathrm{T}_{\mathrm{e}}\right] / \mathrm{R}$ for $\mathrm{T}_{\mathrm{e}}<\mathrm{T}_{\mathrm{S}}$

$\mathrm{C}_{1}$ is not greater than the values below, and no less than 1.0.

$$
C_{1}=\left\{\begin{array}{l}
1.5 \text { for } T_{e}<0.1 \mathrm{~s} \\
1.0 \text { for } T_{e} \geq T_{s}
\end{array}\right.
$$

$\mathrm{T}_{\mathrm{e}}=$ effective fundamental Period of the building under consideration .

$$
T_{e}=T_{i} \sqrt{\frac{K_{i}}{K_{e}}}
$$

$\mathrm{R}=$ Ratio of elastic strength demand to calculated yield strength coefficient.

$$
R=\frac{S_{a}}{V_{y} / W} \cdot C_{m}
$$

$\mathrm{C}_{2}=$ Modification factor to represent the effect of pinched hysteretic shape, stiffness, and strength degradation on maximum displacement response. Values for different framing

\begin{tabular}{|c|c|c|c|c|}
\hline \multirow{2}{*}{$\begin{array}{c}\text { Structural performance } \\
\text { level }\end{array}$} & \multicolumn{2}{|c|}{$\mathrm{T} \leq 0.1$ second } & \multicolumn{2}{|c|}{$T \geq T_{s}$ second } \\
\hline & $\begin{array}{l}\text { Framing } \\
\text { type } 1^{1}\end{array}$ & $\begin{array}{l}\text { Framing } \\
\text { type } 2^{2}\end{array}$ & $\begin{array}{l}\text { Framing } \\
\text { type } 1^{1}\end{array}$ & $\begin{array}{l}\text { Framing } \\
\text { type } 1^{2}\end{array}$ \\
\hline IO & 1 & 1 & 1 & 1 \\
\hline LS & 1.3 & 1 & 1.1 & 1 \\
\hline $\mathrm{CP}$ & 1.5 & 1 & 1.2 & 1 \\
\hline \multicolumn{5}{|c|}{$\begin{array}{l}{ }^{1} \text {.Buildings in which any combination of the following } \\
\text { components, elements, or frames resists more than } 30 \% \text { of the } \\
\text { floor shear at an level. } \\
{ }^{2} \text {. All frames that aren't categorized as Framing Form } 1 \text {. }\end{array}$} \\
\hline
\end{tabular}
systems and structural performance levels shall be calculated from Table 4.

Table 4. Values for Modification Factor $\mathbf{C}_{2}$. 
$\mathrm{C}_{3}=$ Modification factor to represent increased displacements due to dynamic P- $\Delta$ effects. For buildings with a positive post-yield stiffness (maintains its strength during a given deformation cycle, but loses strength in subsequent cycles, the effective stiffness also decreases in subsequent cycles (degradation of cyclic strength)) the value shall be set at 1.0. For buildings with negative post-yield stiffness(Note that the degradation happens during the same cycle of deformation in which yielding occurs, resulting in a negative post-elastic stiffness, (in-cycle strength degradation)), values shall be calculated using equation (17).

$$
C_{3}=1.0+\frac{|\alpha|(R-1)^{3 / 2}}{T_{e}}
$$

Where $\alpha$ is the ratio of post-yield stiffness to elastic stiffness when the nonlinear forcedisplacement relation is characterized by a bilinear relation.

\subsection{FEDERAL EMERGENCY MANAGEMENT AGENCY (FEMA-440, 2004)}

\subsubsection{Improved Procedures for Displacement Modification}

FEMA 440 (2005) recommends that the limitations (capping) allowed by FEMA 356 to the coefficient $\mathrm{C}_{1}$ be abandoned, In addition, a distinction is recognized between two different types of strength degradation that have different effects on system response and performance, this distinction leads to recommendations for the coefficient $\mathrm{C}_{2}$ to account for cyclic degradation in strength and stiffness. It is also suggested that the coefficient $\mathrm{C}_{3}$ be eliminated and replaced with a limitation on strength $(\mathrm{R})$.

a. Maximum Displacement Ratio (Coefficient $\mathrm{C}_{1}$ )

FEMA 356 currently accepts the coefficient $\mathrm{C}_{1}$ to be restricted (capped) for relatively shortperiod structures. FEMA440 suggested that this limitation not be used. This may increase the estimatation of the displacement for some structures. For most structures, the following simplified expression may be used for the coefficient $\mathrm{C}_{1}$ :

$$
C_{1}=1+\frac{R-1}{a T_{e}^{2}}
$$

For periods less than $0.2 \mathrm{~s}$, the value of the coefficient $\mathrm{C}_{1}$ for $0.2 \mathrm{~s}$ may be used. For periods greater than $1.0 \mathrm{~s}, \mathrm{C}_{1}$ may be assumed to be 1.0 .

b. Degrading System Response (Coefficient $\mathrm{C}_{2}$ ) 
FEMA 356 suggested that the $\mathrm{C}_{2}$ coefficient represents the effects of stiffness degradation only. FEMA440 recommended that the displacement prediction must be modified to account the cyclic degradation of stiffness and strength. It recommended that the $\mathrm{C}_{2}$ coefficient must be as follows:

$$
C_{2}=1+\frac{1}{800}\left(\frac{R-1}{T}\right)^{2}
$$

For periods less than $0.2 \mathrm{~s}$, the value of the coefficient $\mathrm{C}_{2}$ for $0.2 \mathrm{~s}$ may be used. For periods greater than $0.7 \mathrm{sec}, \mathrm{C}_{2}$ may be assumed equal to 1.0 for assumption includes the buildings with modern concrete or steel special moment-resisting frames, steel eccentrically braced frames, and buckling-restrained braced frames as either the original system or the system added during seismic retrofit.

c. P- $\Delta$ Effects (Coefficient $\mathrm{C}_{3}$ )

Because of dynamic P- $\Delta$ effects, the displacement modification factor $\mathrm{C}_{3}$ is intended to account for increased displacements. FEMA 440 proposed that the current coefficient $\mathrm{C}_{3}$ has been eliminated and and replaced it with the maximum strength ratio, $\mathrm{R}$, intended to calculate the dynamic instability. Where the value for $\mathrm{R}_{\max }$ is exceeded, a Nonlinear Dynamic Procedures (NDP) analysis is recommended to capture strength degradation and dynamic $\mathrm{P}-\Delta$ effects to confirm the dynamic stability of the building. Nonlinear static procedures are not capable for distinguishing completely between cyclic and in-cycle strength losses. However, insight can be obtained by separating the in-cycle P- $\Delta$ effects from $\alpha_{2}$ (see Fig. 5).

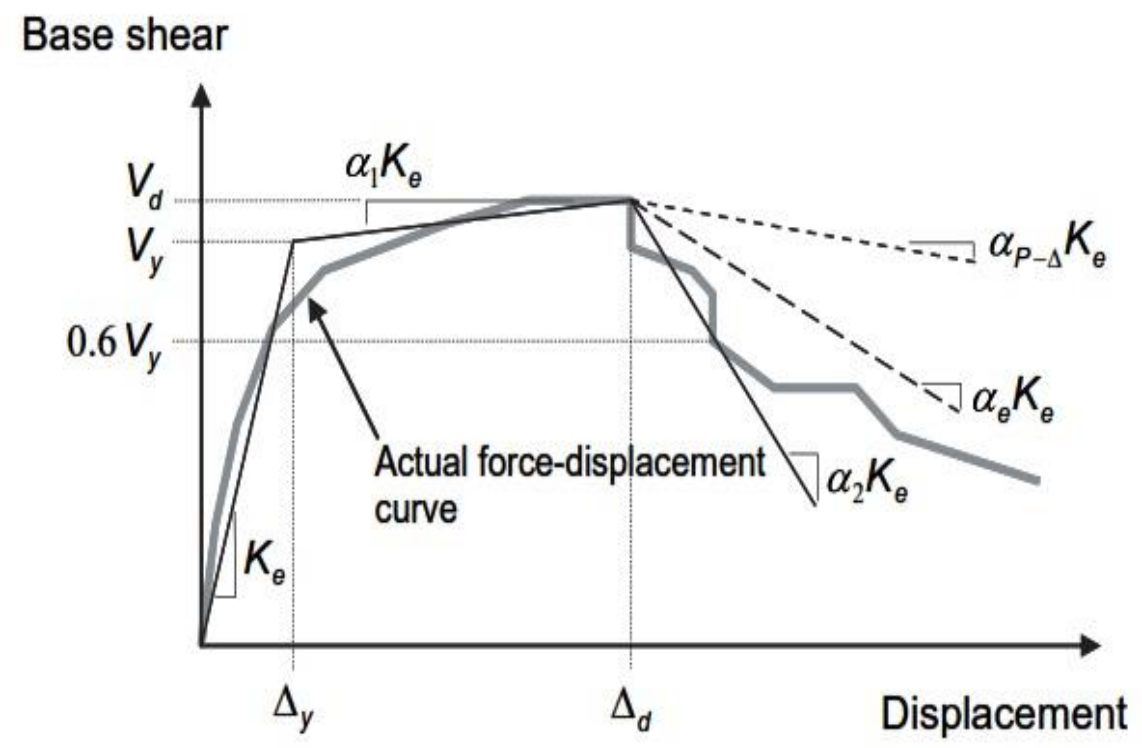

Fig. 6. Idealized Force-Displacement Curves. 
After that, an acceptable post-elastic stiffness can be calculated as

$$
\alpha_{e}=\alpha_{p-\Delta}+\lambda\left(\alpha_{2}-\alpha_{p-\Delta}\right)
$$

Where $0 \leq \lambda \leq 1.0$

FEMA 440 recommended that $\lambda$ must be assigned the value of 0.2 for sites not subject to near field effects and 0.8 for those that are. Displacement amplifications increase as the post-yield negative stiffness (caused by in-cycle strength degradation) ratio $\alpha$ decreases (becomes more negative), as $\mathrm{R}$ increases. Minimum strength (maximum $\mathrm{R}$ ) required avoiding dynamic instability. The recommended limit on the design force reduction, $\mathrm{R}_{\max }$, is as follows:

$$
R_{\max }=\frac{\Delta_{d}}{\Delta_{y}}+\frac{\left|\alpha_{e}\right|^{-t}}{4}
$$

Where

$$
\mathrm{t}=1+0.15 \ln \mathrm{T}
$$

The structural model must appropriately model the strength degradation characteristics of the structure and its components

\subsubsection{Improved Procedures for Equivalent Linearization}

An improved equivalent linearization procedure as a modification to the Capacity-Spectrum Method (CSM) of ATC-40. When equivalent linearization is used as a part of a nonlinear static procedure that models the nonlinear response of a building with a SDOF oscillator, the objective is to evaluate the maximum displacement response of the nonlinear system with an "equivalent" linear system using an effective period, $\mathrm{T}_{\mathrm{eff}}$, and effective damping, $\beta_{\mathrm{eff}}$, (see Fig. 7).

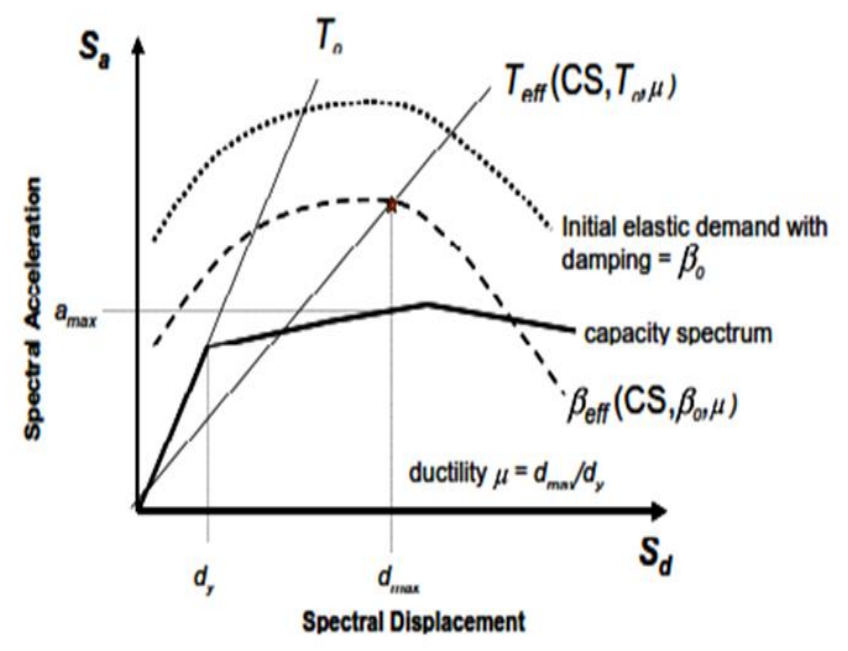

Fig. 7. Damping Values and Effective Period of the Equivalent Linear System. 


\section{a. Effective Damping}

The formulas herein presented apply to any capacity curve, independent of the hysteretic model, type or post-elastic stiffness value $(\alpha)$ used. The effective damping is calculated using the Equations below depending on the structure's level of ductility $\mu$.

For $\mu<4.0$ :

$$
\beta_{\text {eff }}=4.9(\mu-1)^{2}-1.1(\mu-1)^{3}+\beta_{0}
$$

For $4.0 \leq \mu \leq 6.5$ :

$$
\beta_{\text {eff }}=14.0+0.32(\mu-1)+\beta_{0}
$$

For $\mu>6.5$ :

$$
\beta_{\text {eff }}=19\left[\frac{0.64(\mu-1)-1}{[0.64(\mu-1)]^{2}}\right]\left(\frac{T_{e f f}}{T_{0}}\right)^{2}+\beta_{0}
$$

\section{b. Effective Period}

The following equations apply to any capacity spectrum independent of the hysteretic model form or post-elastic stiffness value. The effective period depends on the ductility level and is calculated using the Equations below:

For $\mu<4.0$ :

$$
T_{\text {eff }}=\left\{0.20(\mu-1)^{2}-0.038(\mu-1)^{3}+1\right\}
$$

For $4.0 \leq \mu \leq 6.5$ :

$$
T_{\text {eff }}=[0.28+0.13(\mu-1)+1] T_{0}
$$

For $\mu>6.5$ :

$$
T_{\text {eff }}=\left\{0.89\left[\sqrt{\frac{(\mu-1)}{1+0.05(\mu-2)}}-1\right]+1\right\} T_{0}
$$

Where $\mu$ is the ductility and $\alpha$ is the post-elastic stiffness, measured as follows:

$$
\alpha=\frac{\left(\frac{a_{p i}-a_{y}}{d_{p i}-d_{y}}\right)}{\left(\frac{a_{y}}{d_{y}}\right)}
$$

and

$$
\mu=\frac{d_{p i}}{d_{y}}
$$

\section{c. Spectral Reduction Factor of Effective Damping}

The spectral reduction factor is a function of the effective damping and is called the damping coefficient, $\mathrm{B}\left(\beta_{\mathrm{eff}}\right)$ and is calculated using equation: 


$$
B\left(\beta_{\text {eff }}\right)=\frac{4}{5.6-\ln \beta_{e f f}(\operatorname{in} \%)}
$$

As seen in equation (32), it is used to adjust spectral acceleration ordinates.

$$
\left(S_{a}\right)_{\beta}=\frac{\left(S_{a}\right)_{5 \%}}{B\left(\beta_{e f f}\right)}
$$

\subsection{AMERICAN STANDARD OF CIVIL ENGINEERS (ASCE 41-13, 2013)}

ASCE41-17 depends on the displacement coefficient method to capture the target displacement. The target displacement, $\delta$ at each floor level shall be determined by equation (33).

$$
\delta_{t}=C_{o} C_{1} C_{2} S_{a} \frac{T_{e}^{2}}{4 \pi^{2}} g
$$

where

$\mathrm{C}_{\mathrm{o}}=$ modification factor to relate spectral displacement of an equivalent single degree of freedom (SDOF) system to the roof displacement of multi-degree of freedom (MDOF) system determined using one of the following procedures:

1. The first mode mass participation factor is multiplied by the ordinate of the first mode shape at the control node.

2. The mass participation factor was calculated using a shape vector corresponding to the deflected shape of the building at the target displacement multiplied by the ordinate of the shape vector at the control node.

\begin{tabular}{|c|c|c|c|}
\hline & \multicolumn{2}{|c|}{ Shear Buildings ${ }^{1}$} & Other Buildings \\
\hline $\begin{array}{l}\text { No.of } \\
\text { stories }\end{array}$ & $\begin{array}{c}\text { Triangular } \\
\text {. load } \\
\text { pattern }\end{array}$ & $\begin{array}{l}\text { Uniform. } \\
\text { load pattern }\end{array}$ & Any .load pattern \\
\hline 1 & 1.0 & 1.0 & 1.0 \\
\hline 2 & 1.2 & 1.15 & 1.2 \\
\hline 3 & 1.2 & 1.2 & 1.3 \\
\hline 5 & 1.3 & 1.2 & 1.4 \\
\hline+10 & 1.3 & 1.2 & 1.5 \\
\hline
\end{tabular}

3. The appropriate value from Table 5.

Table 5. Modification Factor Co values. 
$\mathrm{C}_{1}=$ modification factor to relate the estimated maximum inelastic displacements to displacements calculated for the linear elastic response. For periods less than $0.2 \mathrm{sec}, \mathrm{C}_{1}$ does not need not be taken greater than the value at $\mathrm{T}=0.2 \mathrm{sec}$. For periods greater than $1.0 \mathrm{sec}, \mathrm{C}_{1}$ $=1.0$.

$$
C_{1}=1+\frac{R-1}{a T_{e}^{2}}
$$

where, $\mathrm{a}=$ site class factor $=130$ site Class $\mathrm{A}, \mathrm{B} ;=90$ site Class $\mathrm{C}$, and $=60$ site Class $\mathrm{D}, \mathrm{E}$, and $\mathrm{F}$.

$\mathrm{C}_{2}=$ modification factor to represent the effect of pinched hysteresis shape, cyclic stiffness degradation, and strength deterioration on maximum displacement response. For periods greater than $0.7 \mathrm{sec}, \mathrm{C}_{2}=1.0$

$$
C_{2}=1+\frac{1}{800}\left(\frac{R-1}{T_{e}}\right)^{2}
$$

The strength ratio $\mathrm{R}$ must be determine using the equation (36).

$$
R=\frac{S_{a}}{V_{y} / W} \cdot C_{m}
$$

$\mathrm{C}_{\mathrm{m}}$ taken as the effective modal mass participation factor determined for the fundamental mode using an eigenvalue analysis shall be acceptable. $\mathrm{C}_{\mathrm{m}}$ shall be taken as 1.0 if the fundamental period, $\mathrm{T}$, is greater than $1.0 \mathrm{sec}$.

The maximum strength ratio, $\mathrm{R}_{\max }$, must be determined by equation (37) for buildings with negative post-yield stiffness.

$$
\mathrm{R}_{\max }=\frac{\Delta_{d}}{\Delta_{y}}+\frac{\left|\alpha_{d}\right|^{-\mathrm{h}}}{4}
$$

where

$\Delta_{\mathrm{d}}=$ peak displacement or displacement at maximum base shear.

$\Delta_{\mathrm{y}}=$ displacement at the effective yield strength.

$\mathrm{h}=1+0.15$. In $\mathrm{T}$, and

$\alpha_{\mathrm{e}}=$ equation (38) defines the effective negative post-yield slope ratio.

$$
\alpha_{e}=\alpha_{p-\Delta}+\lambda\left(\alpha_{2}-\alpha_{p-\Delta}\right)
$$

where

$\alpha_{2}=$ negative post-yield slope ratio. This include P- $\Delta$ effects, in-cycle degradation, and cyclic degradation;

$\alpha_{\mathrm{p}-\Delta}=\mathrm{P}-\Delta$ effects cause a negative slope ratio; and

$\lambda=$ near field effect factor:

$=0.8$ if $\mathrm{S} 1 \leq 0.6($ Maximum Considered Earthquake, $\mathrm{MCE}) ;=0.2$ if $\mathrm{S} 1<0.6(\mathrm{MCE})$. 


\subsection{Euro code 8 (EC-8, Part 3)}

$\mathrm{N}_{2}$ method, the first proposed by Fajfar and Fischinger, (1988) is represnted the Nonlinear Static Procedures (NSP) adopted by Euro code 8 and and considered as modifiying version of the capacity spectrum method (CSM). Indeed, the estimation of seismic demand is based on the use of inelastic spectra in the $\mathrm{N}_{2}$ method instead of highly damped elastic spectra, as per the CSM. The steps of the capacity spectrum method are defined herein:

Step (1) and Step (2) are the same steps of the capacity spectrum method with ATC-40. Step (3): Pushover analysis

Pushover analysis is performed by applying a monotonically increasing pattern of lateral forces to the structure, (see Fig. 8). These forces represent the inertial forces induced in the structure by the ground motion. Any reasonable distribution of lateral loads can be used in the $\mathrm{N}_{2}$ method. The Euro code 8 recommends that the use of at least two distributions: a first mode proportional load pattern and a uniform load pattern.

The vector of the lateral loads $\bar{F}$ used in the pushover analysis proportional to the first mode is determined as:

$$
\bar{F}=p M \Phi
$$

The lateral force in the i-th level is proportional to the component $\Phi$ of the assumed displacement shape $\Phi_{i}$ weighted by the storey mass $m_{i}$

$$
\bar{F}=p m_{i} \Phi_{i}
$$

The vector of the lateral loads $\bar{F}$ used in the pushover analysis with a uniform distribution is determined as:

$$
\begin{aligned}
& \bar{F}_{\text {uni }}=p M \\
& \bar{F}_{\text {unij }}=p m_{i}
\end{aligned}
$$

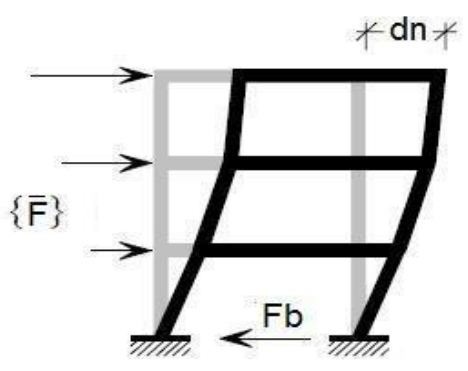

Fig. 8. Pushover Analysis of the MDOF Model. 
The $\mathrm{N}_{2}$ method prescribes that the figure above should represent the base shear $\left(\mathrm{F}_{\mathrm{b}}\right)$ and the displacement at the center of mass of the roof $\left(\mathrm{d}_{\mathrm{n}}\right)$.

\section{Step (4): Equivalent SDOF system}

The MDOF structure should be transformed into an equivalent SDOF system. The definition of the transformation factor $\Gamma$ is based on the equation of motion of a MDOF system

$$
M \cdot \ddot{U}+R=-M \cdot 1 \cdot a
$$

Where $\mathrm{U}$ is the displacement vector, $\ddot{U}$ is the acceleration vector, $\mathrm{M}$ is a diagonal mass matrix, $\mathrm{R}$ is the internal forces vector, 1 is a unit vector and a is the ground acceleration as a function of time. The deformed pattern $\Phi$ is assumed to be constant during the structural response to the earthquake. The displacement vector is then written as equation (44).

$U=\Phi \cdot d_{n}$

where $d_{n}$ is the top displacement. The $\Phi$ is normalized to have its component at the top equal to 1 . The internal forces $\mathrm{R}$ are equal to the statically applied external loads $\mathrm{F}^{-}$.

$\bar{F}=\mathrm{R}$

Equations (39 and 44) into equation (45) and multiplying the equation by $\Phi$, it follows:

$\Phi^{T} \cdot M \cdot \Phi \cdot \dot{d}_{n}+\Phi^{T} \cdot M \cdot \Phi \cdot p=-\Phi^{T} \cdot M \cdot 1 \cdot a$

The SDOF system's equation of motion can be written as:

$m^{*} \cdot \ddot{d}^{*}+F^{*}=-m^{*} \cdot a$

where $m^{*}$ is the equivalent mass of the SDOF system and it is calculated using equation (48)

$m^{*}=\Phi^{T} \cdot M \cdot 1=\Sigma m_{i} \Phi_{i}$

The transformation of the MDOF to the SDOF, the system is made in the $\mathrm{N}_{2}$ method using equations (49) and (50)

$$
\begin{aligned}
d^{*} & =\frac{d_{n}}{\Gamma} \\
F^{*} & =\frac{F_{b}}{\Gamma}
\end{aligned}
$$

where $d^{*}, F^{*}$ are the displacement and base shear of the SDOF system. According to equation (51), the transition element from the MDOF to the SDOF model is: 


$$
\Gamma=\frac{\Phi^{T} \cdot M \cdot 1}{\Phi^{T} \cdot M \cdot \Phi}=\frac{\sum m_{i} \Phi_{i}}{\sum m_{i} \Phi_{i}^{2}}=\frac{m^{*}}{\sum m_{i} \Phi_{i}^{2}}=\frac{\Sigma F_{i}}{\Sigma\left(\frac{F_{i}^{2}}{m_{i}}\right)}
$$

The transformation factor $\Gamma$ is usually called the modal participation factor. The SDOF capacity curve is defined by the displacement of the SDOF ( $\left.\mathrm{d}^{*}\right)$ and base shear of this system $\left(F^{*}\right)$ as shown (see Fig. 9).

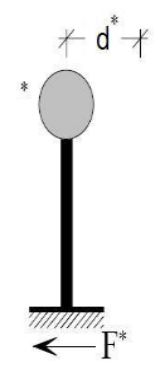

Fig. 9. Equivalent SDOF system.

Euro code 8 prescribes a simplified elastic-perfectly plastic bilinear approximation of the SDOF capacity curve (see Fig. 10). The smooth curve represents the bilinear of the SDOF capacity curve.

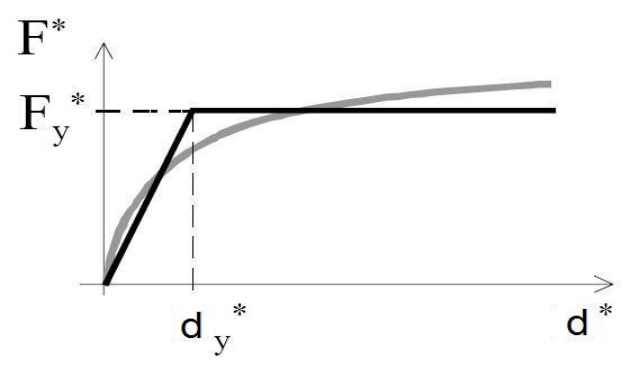

Fig. 10. SDOF capacity curve and its bi linearization

The elastic period of the idealized bilinear SDOF system $\mathrm{T}^{*}$ is computed according to equation (52):

$T^{*}=2 \pi \sqrt{\frac{m^{*} d_{y}^{*}}{F_{y}^{*}}}$

$\mathrm{N}_{2}$ method assumes that in the medium/long period range $\left(T^{*} \geq T_{c}\right)$ the equal displacement rule applies, i.e. the displacement of the inelastic system $\mathrm{Sd}$ is equal to the displacement of the associated elastic system Sde characterized by the same period $T^{*}$, where $T_{c}$ is the characteristic period of the ground motion, which is defined as the transition period between 
the constant acceleration section of the response spectrum (corresponding to the short period range) and the constant velocity segment of the response spectrum (corresponding to the medium period range) (see Fig. 11).

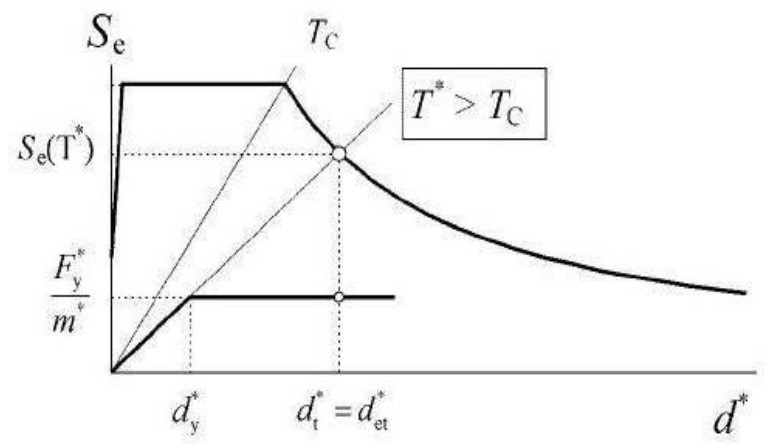

Fig. 11. Long-period range.

This means that in the above mentioned period range $\mathrm{R}_{\mu}=\mu$. Seismic demand in terms of inelastic displacement can be obtained by intersecting the radial line with the elastic demand spectrum corresponding to the SDOF system period. In the case of short-period structures $\left(\mathrm{T}^{*}<\mathrm{T}_{\mathrm{C}}\right)$ the inelastic displacement is larger than the elastic one and the equal displacement rule does not apply anymore, (see Fig. 12). Consequently $\mathrm{R}_{\mu}<\mu$ and it can be calculated as the ratio between the elastic acceleration demand capacity Sae and the inelastic acceleration Say. The inelastic displacement demand is, in this case, equal to $S_{d}=\mu \cdot D^{*} y$ being $D^{*} y$ the yielding displacement of the SDOF system. The ductility factor can be derived from the reduction factor by the relation:

$\mu=\left(R_{\mu}-1\right) \frac{T_{C}}{T^{*}}+1$

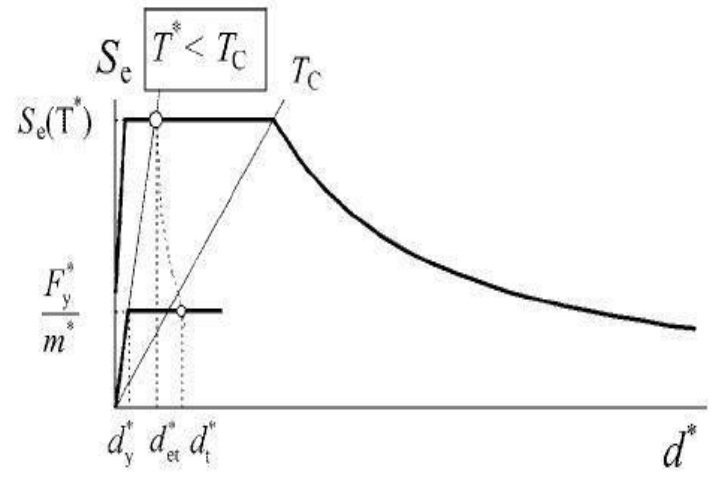

Fig. 12. Short period range.

In both cases $\left(T^{*} \geq T_{C}\right.$ and $\left.T^{*}<T_{C}\right)$ the inelastic acceleration demand $S_{a}$ is equal to the elastic one $S_{a e}$ and it can be verified at the intersection of the radial line corresponding to the period of the SDOF system with the elastic demand spectrum. 


\subsection{Japanese Standard}

Three screening levels have been introduced in the Japanese standard (Japanese code, 2001) for seismic capacity evaluation. Seismic index of the structure for each story

Is $=E_{0} \cdot S_{D} \cdot T$

where Eo is the primary seismic index of screening levels. The primary seismic index of structure Eo of the i-th story in an n-story building is given as a product of the strength index. $\mathrm{C}$, ductility index $\mathrm{F}$, and $\alpha$ is the effective strength factor, differently in each screening level as shown in the Table $6 . \mathrm{S}_{\mathrm{D}}$ is introduced to adjust the basic seismic index by measuring the effects of horizontal, vertical shapes, and the mass and stiffness irregular distribution of the structure. $T$ is a modification factor of the basic seismic index which evaluates the effects of cracks, deflection, and aging of the building. $T$ value will be a range of 0.7 to 0.9 but if there is no defect, the $\mathrm{T}$ value is 1 . Building older than 30 years have a $\mathrm{T}$ value of 0.8 , but for newer buildings less than 19 years old the T value should be equals to 1 .

Table 6. Values of the primary seismic index $\left(E_{0}\right)$.

\begin{tabular}{cc}
\hline Screening & Primary Seismic Index( $\left.\mathbf{E}_{\mathbf{0}}\right)$ \\
\hline $\begin{array}{c}\text { First } \\
\text { Screening }\end{array}$ & $E_{0}=\frac{n+1}{n+i}\left(C_{w}+\alpha_{1} C_{e}\right) \times F_{w}$ \\
\hline $\begin{array}{c}\text { Second } \\
\text { Screening }\end{array}$ & $E_{0}=\frac{n+1}{n+i}\left(C_{s c}+\alpha_{2} C_{w}+\alpha_{3} C_{c}\right) \times F_{s c}$ \\
\hline $\begin{array}{c}\text { Third } \\
\text { Screening }\end{array}$ & $E_{0}=\frac{n+1}{n+i} \sqrt{E_{1}^{2}+E_{2}^{2}+E_{3}^{2}}$ \\
\hline $\begin{array}{c}\text { Forth } \\
\text { Screening }\end{array}$ & $E_{0}=\frac{n+1}{n+i}\left(C+\sum_{j} \alpha_{j} C_{j}\right) \times F_{1}$ \\
\hline
\end{tabular}

Seismic demand index $\left(\mathrm{I}_{\mathrm{so}}\right)$ regardless of the number of stories in the building:

$$
\mathbf{I}_{\mathrm{so}}=\text { Es. Z. G. U }
$$

where

$\mathrm{E}_{\mathrm{s}}$ is the basic seismic demand index of the structure, standard values of which shall be selected as 0.8 for the first level screening and 0.6 for the second and third level screenings.

$\mathrm{Z}$ is the zone index, namely the modification factor accounting for the seismic activities and intensities expected in the region of the site.

$\mathrm{G}$ is a ground index, namely the modification factor accounting for the effects of the amplification of the surface soil, geological conditions, and soil-structure interaction on the expected earthquake motions. $U$ is the usage index, namely the modification factor accounting for the building.

If

Is $\geq$ Iso 
If equation 56 is satisfied, the building may be assessed to be "safe". Otherwise, the building should be assessed to be "an uncertainty" in seismic safety and need to retrofit.

\subsection{NZS1170.5 2004}

The target displacement of (NZS1170.5, 2004) is calculated by using the coefficient method, as described in FEMA-356.

$$
\delta=C_{0} C_{1} C_{2} C_{3} C(T) \frac{T_{c}^{2}}{4 \pi^{2}} g
$$

where the coefficients take the same roles in modifying the expected elastic displacement. Expressions for them are redefined here to better reflect the intent of NZS1170.5. $\mathrm{C}_{0}$ will equal (1) as we plot the deflection of the dynamic center of mass.

$\mathrm{C}_{1}$ accounts for the variation between the response of an elasto-plastic and elastic SDF systems and can be obtained from clauses 5.2 and 7.2.1.1 of the Standard expressed as

$$
C_{1}=\mu^{*} S p / k_{\mu}
$$

Since variations in the response of systems with a pinched hysteretic shape and stiffness and strength degradation are not taken into account in NZS1170.5, $\mathrm{C}_{2}$ would equal "1".

The increased displacements caused by dynamic P-delta effects are accounted for by $\mathrm{C}_{3}$. This can be calculated using the Standard as follows:

$$
C_{3}=1+\beta \theta
$$

NZS1170.5 provides limitations as to which buildings require $\mathrm{P}-\Delta$ effects included in the analyses. This is a pragmatic approach to allow simple regular buildings to be quickly designed with the knowledge that other conservative clauses in the Standard will provide for the shortfall in strength. It is recommended here, that where the NSP procedure is used in a seismic assessment procedure and the building has not been designed to modern Standards, $\mathrm{C}_{3}$ as per equation 59 be included in the analysis of all buildings. $\mathrm{C}(\mathrm{T})$ is the ordinate of the elastic hazard spectrum as per clause 3.1.1 of the Standard.

\section{CONCLUSIONS}

Referring to the review concerning the seismic evaluation and retroofitting, the following remarks can be concluded: 
1. Japanese Standard depends on the numerical technique. It takes the strength and stiffness deterioration and torsional effect into account in the seismic assessment.

2. The improvement CSM and DCM of (FEMA-440) focused on the effect of degradation of stiffness and the dynamic properties changes associated with damage. It doesn't take the effect of irregularity in the plan or elevation into consideration.

3. ATC-40, FEMA273/356, FEMA440, and ASCI 41-13 are considered the most important than Euro code 8 - Part 3. FEMA440 also states that the procedures used in FEMA273/356 and ATC-40 are insufficient to capture the dynamic instability phenomenon.

4. Static nonlinear analysis (Pushover analysis) Procedures are considered to be a very realistic method for evaluating structural seismic performance, and it is introduced in this context as an effective tool for performance assessment.

5. Despite the large efforts of researchers aimed at the improvement of NSPs for a reliable application to irregular buildings. It is seen these developments have not yet transposed to both European and American codes. For this reason, these codes are still in need of improvement regarding specific prescriptions concerning the seismic analysis of irregular structures.

6. The results of the CSM method according to ATC-40 and an improved equivalent linearization procedure adopted by FEMA-440 differed because the equivalent linearization procedure relied on new expressions to assess effective period and effective damping.

\section{ACKNOWLEDGMENTS}

The authors would like to thank Mustansiriyah University (www.uomustansiriyah.edu.iq) Baghdad - Iraq for its support in the present work.

\section{REFERENCES}

Giordano, M., Guadagnuolo and Faella G. (2008) "Pushover Analysis of Plan Irregular Masonry Buildings" The 14 World Conference on Earthquake Engineering, Beijing, China.

Hamraj. M. (2014) "Performance Based Pushover Analysis of R.C.C Frames for Plan Irregularity", International Journal of science, Engineering and Techonology, Vol.7.

Mwafy A.M. and Elnashai.A.S. (2001) "Push Versus Dynamic Collapse Analysis of R/C Buildings", International Journal of Modern Trends in Engineering and Science, Vol.4. 
Elnashai A. S. and Di Sarno L., (2008), "Fundamentals of Earthquake Engineering”. Wiley and Sons, UK.

Yön, B., Sayın, E. and Onat, O. (2017), “Earthquakes and Structural Damages”, Earthquakes Tectonics, Hazard and Risk Mitigation, DOI: 10.5772/65425.

Applied Technology Council, (1996), "Seismic Evaluation and Retrofit of Concrete Buildings”, Report No. SSC 9601: ATC-40, Vol.1, Redwood City, California.

Federal Emergency Management Agency, (1997) "NEHRP Guidelines for the Seismic Rehabilitation of Buildings", FEMA-273", Washington, D.C.

Federal Emergency Management Agency, (2000) "Prestandard and Commentary for the Seismic Rehabilitation of Buildings”, FEMA-356, Washington, D.C.

ATC, Applied Technology Council. (2005) "Improvement of Nonlinear Static Seismic Analysis Procedures”, FEMA440 Report. Redwood City, CA.

ASCE, "Seismic analysis of safety-related nuclear structures and commentary" (2013). ASCE standard no.004-98, American Society of Civil Engineering.

CEN (2005a), EN 1998-3 Eurocode 8; "Design of structures for earthquake resistance, part 3: assessment and retrofitting of buildings" (1998), European Committee for standardization.

Fajfar, P.; Fischinger, M.(1988), "N2-A Method for Nonlinear seismic analysis of regular buildings", In Proceedings of the Ninth World Conference Earthquake Engineering, Tokyo, Japan.

The Japan Building Disaster Prevention Association (JBDPA), (2001), "Standard for Seismic Evaluation of Existing Reinforced Concrete Buildings” (JBDPA, Tokyo).

NZS1170.5. (2004), "Structural Design Actions Part 5: Earthquake Actions - New Zealand", Standards New Zealand, 2004. 